\title{
Prevalence of hyperhomocysteinaemia in a Chinese elderly population
}

\author{
Quan-Gang Qu', Jin-Ji Gao ${ }^{2}$ and Jian-Meng Liu ${ }^{1, *}$
}

${ }^{1}$ Institute of Reproductive and Child Health, Peking University Health Science Center, 38 Xueyuan Road, Haidian District, Beijing 100191, People's Republic of China: ${ }^{2}$ The Maternal and Child Health Care Hospital, Yuanshi

County, Shijiazhuang City, Hebei Province, People's Republic of China

Submitted 29 November 2009: Accepted 10 February 2010: First published online 18 March 2010

\begin{abstract}
Objective: To evaluate plasma homocysteine (Hcy) levels and prevalence rates of hyperhomocysteinaemia (HHCY) in elderly Chinese individuals.

Design: A cross-sectional study.

Setting: The study was conducted in 2006 in two counties from the north and the south of China.

Subjects: A total of 810 individuals aged $65-74$ years were recruited. Demographic characteristics and lifestyle factors were assessed through questionnaire interviews and physical examination. Hcy and folate levels were measured in blood samples. The distribution of Hcy level was analysed according to Hcy-related factors.

Results: Northerners had higher Hcy levels $(18.42 \mu \mathrm{mol} / \mathrm{l})$ than southerners $(10 \cdot 20 \mu \mathrm{mol} / \mathrm{l})$. Plasma Hcy was higher in men than in women and greater in smokers than in non-smokers. The prevalence rate of HHCY was $51 \cdot 6 \%$ in the north and $10 \cdot 1 \%$ in the south $(P<0 \cdot 001)$. Hcy and plasma folate showed an inverse correlation (Spearman's $r=-0 \cdot 44, P<0 \cdot 001$; partial $r=-0 \cdot 229, P<0 \cdot 001$ ). Region, gender, alcohol consumption and plasma folate were associated with HHCY among these elderly populations.

Conclusions: The results demonstrated that plasma Hcy levels and the prevalence rates of HHCY in Chinese elderly are considerably higher than those found in other countries, and substantial regional variations occur within China. The predominant determining factors of HHCY were region, gender, alcohol consumption and plasma folate. The elevated Hcy levels among elderly Chinese populations need to be decreased urgently.
\end{abstract}

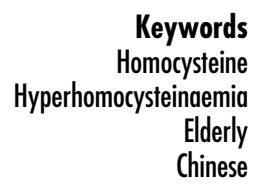

Hyperhomocysteinaemia (HHCY) has been suggested as a risk factor for developing coronary artery disease, myocardial infarction and stroke ${ }^{(1,2)}$. Epidemiological studies have documented that, in general populations, the most common risk factor for having HHCY is suboptimal or deficient vitamin (e.g. folate) status. Moreover, homocysteine (Hcy) levels also increase significantly with age and HHCY prevalence rates have been reported to be higher in the elderly than in other age groups ${ }^{(3-6)}$. Thus, risk factors for HHCY may vary by life stage and nutritional background. Findings from younger age groups and populations with better nutritional status are unlikely to be applicable to the elderly. However, in view of the fact that both overall nutritional status and health status are associated with elevated risk of HHCY, the prevalence rates of HHCY among elderly populations should be evaluated.

Developed countries have carried out several large-scale population-based surveys to evaluate Hcy levels in the elderly, but there is a paucity of equivalent data from developing countries. In China, previous studies conducted among elderly individuals were mostly hospital-based, with limitations on study design, selection criteria and sample size. Cross-sectional surveys addressing the issue of differential relationships between Hcy levels and demographic characteristics and lifestyle factors among elderly Chinese populations (aged 65-74 years) are not yet available.

Thus the main purposes of the present study were to characterize the distribution of Hcy levels and identify determining factors associated with HHCY in Chinese individuals aged 65-74 years who live in northern and southern counties of China.

\section{Materials and methods}

\section{Study design and population}

We chose two counties as field sites: one (Yuanshi County, Hebei Province) in the north (near Beijing) and 
the other (Nanfeng County, Jiangsu Province) in the south (near Shanghai). In each region, two to four townships were selected so as to provide sufficient potentially eligible volunteers. Study participants were local residents and from the selected townships. An eligible person was aged $65-74$ years in 2006. The first stage of the study involved providing local information and distributing informed consent forms to 1600 potentially eligible individuals in the two regions; 1200 (75\%) individuals agreed to participate in the recruitment process. Recruitment included questionnaire interviews, physical examinations and blood sample collection. Trained health workers were responsible for each recruitment step according to standard protocols. Researchers from Peking University were in charge of quality control. On the basis of data collected through recruitment, eligible participants were ascertained by researchers. Those who met any exclusion criterion could not participate in the study. Exclusion criteria included known CHD, hypertension, cancer, severe renal and liver diseases, diabetes, current use ( $\leq 6$ months) of vitamins or other supplements, and taking medications known to interfere with folate metabolism (e.g. methotrexate). In our study, the main reasons for exclusion were hypertension (60\%), other chronic diseases (22\%) and vitamins taken in the past 6 months (4\%). Eventually, $810(67 \cdot 5 \%)$ eligible individuals from 1200 consenting individuals were included in the study, with 405 subjects in each region. Within regions, the participants were distributed equivalently by gender and age groups (65-69 and 70-74 years old). Therefore, our analyses were based on 810 individuals with complete data.

\section{Covariates}

Demographic information and lifestyle factors were obtained by questionnaire interviews. BMI was calculated as $\mathrm{kg} / \mathrm{m}^{2}$ from weight and height values. Current smoking was defined as smoking more than 1 cigarette/d for at least 1 month and still smoking. Individuals who were exsmokers were counted as 'ever smoking' as a dichotomous variable. The rest were considered non-smokers. Alcohol consumption (including liquor, beer and wine) was classified into two categories: non-drinker and drinker.

\section{Blood sample collection and bomocysteine analyses}

The 810 eligible participants were required to fast overnight before blood collection. Blood samples were drawn and collected in $\mathrm{K}_{3}$ EDTA-containing Vacutainer tubes (Becton Dickinson, Franklin Lakes, NJ, USA), held at $4{ }^{\circ} \mathrm{C}$ and centrifuged at $3000 \mathrm{~g}$ for $15 \mathrm{~min}$. Plasma and red blood cells were separated and frozen at $-20^{\circ} \mathrm{C}$ within $1 \mathrm{~h}$ after collection. All specimens were transported on dry ice to the central laboratory at the Institute of Reproductive and Child Health, Peking University, and stored at $-70^{\circ} \mathrm{C}$ until the assays were performed. Plasma folate concentrations were determined by a microbial assay
(Lactobacillus casei) using a ninety-six-well plate as described by O'Broin and Kelleher ${ }^{(7)}$. Plasma Hcy measurements were carried out by HPLC with fluorometric detection. In the laboratory, intra- and inter-assay $\mathrm{CV}$ across the full range of concentrations were $9 \%$ for plasma folate and $8 \%$ for Hcy. Repeat Hcy concentrations were measured for a sample of fifty individuals in our laboratory after all assessments were completed, and Spearman's correlation coefficient between the before and after values for the same person was $0 \cdot 86(P<0 \cdot 001)$. In addition, the assessment of plasma folate was replicated for a sample of 100 individuals by the chemiluminescence method (Beckman Coulter, Fullerton, CA, USA) in a qualified laboratory. The Spearman's correlation coefficient of two values performed by various methods was $0.93(P<0 \cdot 01)$.

Individuals were classified as having HHCY if they had elevated Hcy concentration $\geq 16 \cdot 0 \mu \mathrm{mol} / \mathrm{l}^{(8)}$. Individuals were classified as having plasma folate deficiency if they had plasma folate concentration $\leq 6 \cdot 8 \mathrm{nmol} / 1^{(9)}$.

\section{Etbical approval}

The study was approved by the Institutional Review Boards of Peking University Health Science Center. All invited participants provided oral informed consent.

\section{Statistical methods}

Because the distributions of Hcy and plasma folate concentrations were positively skewed, natural logarithmic transformations were used to normalize their distributions. The geometric means as well as the $95 \%$ confidence intervals were also determined. Student's $t$ test and one-way ANOVA were used to compare means. The significance of categorical variables was assessed by the $\chi^{2}$ test or Fisher's exact test. Logistic regression was used to estimate crude odds ratios of each variable alone in developing HHCY. Adjusted odds ratios were also determined after controlling for other factors (region, age, gender, BMI, occupation, educational background, hypertension, smoking and alcohol consumption). Spearman's correlation coefficients and probabilities were calculated for the relationship between Hcy and plasma folate in continual quantitative variables. Subgroup analyses for certain risk factors were also conducted in females according to menopausal status and in males according to current smoking status.

The data were analysed with the SPSS statistical software package version $11 \cdot 0$ (SPSS, Beijing, China). All $P$ values were two-sided at $\alpha$ level of $0 \cdot 05$.

\section{Results}

Selected characteristics of the study population are shown separately by region in Table 1 . The demographic characteristics were similar between southerners and northerners. No significant differences were observed in current smoking, health status and medicine use. 
Table 1 Characteristics of the study population by region: elderly Chinese individuals $(n 810)$ aged 65-74 years, 2006

\begin{tabular}{|c|c|c|c|}
\hline & North ( $n$ 405) & South (n 405) & $P$ valuet \\
\hline Age (years) & & & 0.23 \\
\hline Mean & 68 & 69 & \\
\hline SD & $3 \cdot 32$ & $2 \cdot 86$ & \\
\hline Male (\%) & $49 \cdot 9$ & $49 \cdot 6$ & 0.94 \\
\hline Ethnicity, Han (\%) & $99 \cdot 5$ & $99 \cdot 5$ & - \\
\hline Occupation, farmer (\%) & $95 \cdot 6$ & $86 \cdot 1$ & $<0.001$ \\
\hline Education, lower than junior school (\%) & $93 \cdot 1$ & $95 \cdot 8$ & 0.06 \\
\hline Chronic disease family history, yes (\%) & $2 \cdot 7$ & $17 \cdot 5$ & $<0.001$ \\
\hline Current health status, wellness (\%) & $97 \cdot 8$ & $99 \cdot 3$ & 0.08 \\
\hline Medicine use, yes (\%) & 16 & 17 & 0.71 \\
\hline Current smoking, yes (\%) & $25 \cdot 4$ & $27 \cdot 2$ & 0.58 \\
\hline Ever smoking, yes (\%) & $26 \cdot 4$ & $38 \cdot 0$ & $<0.001$ \\
\hline Alcohol consumption, yes (\%) & $15 \cdot 9$ & $28 \cdot 4$ & $<0.001$ \\
\hline BMI $\left(\mathrm{kg} / \mathrm{m}^{2}\right)$ & & & 0.004 \\
\hline Mean & $23 \cdot 12$ & $23 \cdot 79$ & \\
\hline SD & $3 \cdot 32$ & $3 \cdot 25$ & \\
\hline Systolic blood pressure $(\mathrm{mmHg})$ & & & 0.38 \\
\hline Mean & 141 & 140 & \\
\hline SD & 16 & 17 & \\
\hline Diastolic blood pressure $(\mathrm{mmHg})$ & & & $<0.001$ \\
\hline Mean & 82 & 74 & \\
\hline SD & 8 & 8 & \\
\hline $\mathrm{Hb}(\mathrm{g} / \mathrm{l})$ & & & $<0.001$ \\
\hline Mean & 151 & 137 & \\
\hline SD & 17 & 17 & \\
\hline Plasma folate $(\mathrm{nmol} / \mathrm{l})$ & & & $<0.001$ \\
\hline Geometric mean & $10 \cdot 06$ & $14 \cdot 17$ & \\
\hline $95 \% \mathrm{Cl}$ & $9 \cdot 57,10 \cdot 57$ & $13 \cdot 44,14 \cdot 94$ & \\
\hline Plasma folate deficiency (\%) & $31 \cdot 0$ & $7 \cdot 7$ & $<0.001$ \\
\hline
\end{tabular}

t $P$ value from $t$ test for quantitative variables and $\chi^{2}$ test for qualitative variables.

Compared with southerners, northerners had lower average BMI, less alcohol consumption, less smoking exposure (as indicated by ever smoking), and fewer had a family history of chronic disease. In addition, northerners were much more likely to have higher $\mathrm{Hb}$ levels and diastolic blood pressure than southerners, whereas their systolic blood pressures were similar.

The mean plasma folate levels were relatively low in this study population, but southerners appeared to be in better nutritional status than northerners, with significantly higher levels and corresponding lower deficiency rates.

\section{Homocysteine concentrations}

The distribution curves of plasma Hcy were skewed positively, but the curve for northerners had a very long tail towards high values (Fig. 1). Geometric means of Hcy according to demographic and lifestyle factors by region are shown in Table 2. Overall, the mean Hcy level of northerners was $18 \cdot 42 \mu \mathrm{mol} / \mathrm{l}(95 \% \mathrm{CI} 17 \cdot 40,19 \cdot 50 \mu \mathrm{mol} / \mathrm{l})$ and nearly twice the level of southerners, i.e. $10 \cdot 20 \mu \mathrm{mol} / \mathrm{l}(95 \%$ CI $9 \cdot 84,10.58 \mu \mathrm{mol} / \mathrm{l})$, thus being significantly higher in the north than in the south $(P<0 \cdot 01)$.

Gender and smoking status differences in Hcy concentrations among both northerners and southerners were notable: men had higher Hcy levels than women, smokers higher than non-smokers. The absolute differences in Hcy concentrations between genders were of approximately similar magnitude as the corresponding absolute difference between smokers and non-smokers, and were greater than those for other factors. In each region, Hcy levels were not significantly influenced by other factors, except educational background in the south $(P<0 \cdot 01$, Table 2).

\section{Prevalence rate of hyperbomocysteinaemia}

The prevalence rate of HHCY was significantly higher in the north than in the south $(P<0 \cdot 01)$, as shown in Table 3. Overall, HHCY (Hcy $\geq 16 \cdot 0 \mu \mathrm{mol} / \mathrm{l})$ was detected in $209(51 \cdot 6 \%)$ northerners and forty-one $(10 \cdot 1 \%)$ southerners, i.e. nearly five times as many in the north as in the south.

In each region, the prevalence rates of HHCY were observed to be higher in men than women and in smokers than non-smokers. However, the gender and smoking status differences were found to be significant only in the north $(P<0.01$ for both), while neither of them was of significance in the south $(P=0 \cdot 13)$. No statistically significant differences in HHCY prevalence rates were observed for other factors (Table 3).

We applied a logistic regression model to determine the association between each factor and HHCY, as shown in Table 4. Results showed that northerners had nine-fold higher odds of having HHCY than those living in the south. Men had a nearly $75 \%$ increased risk of HHCY compared with women. In addition, those who were 


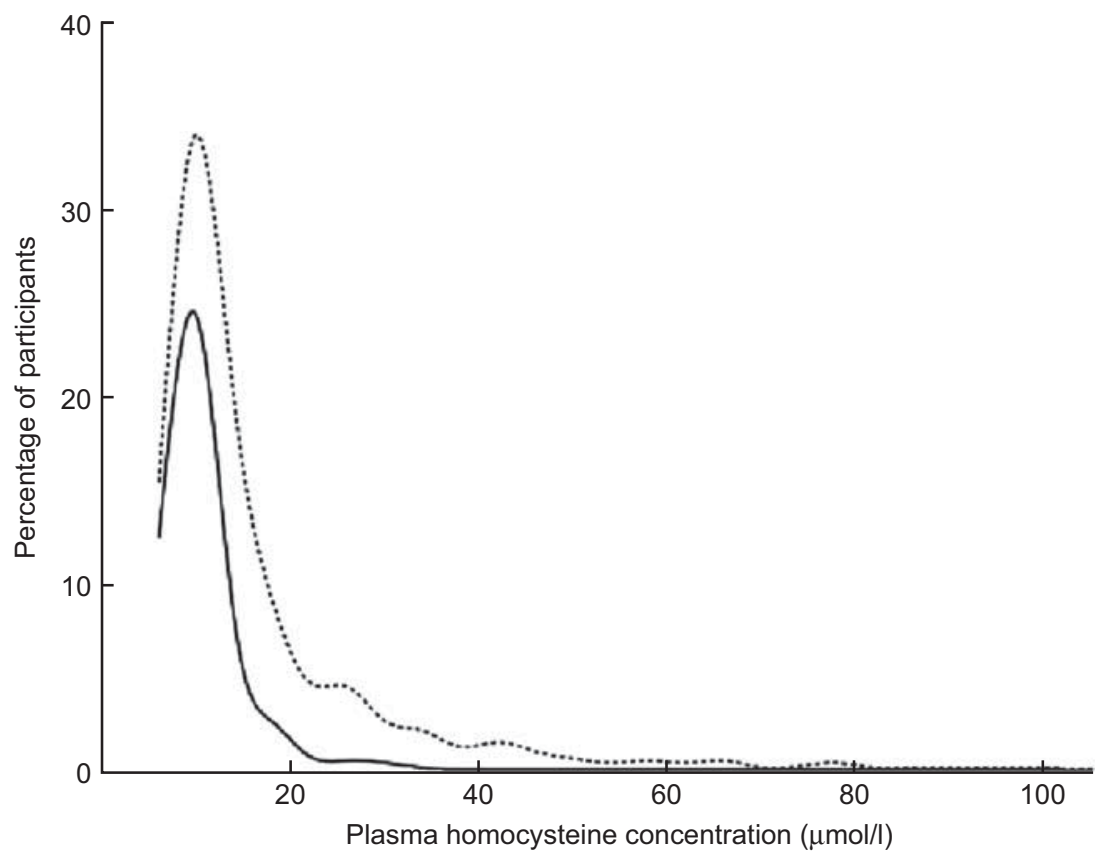

Fig. 1 Distribution of plasma homocysteine concentrations among elderly Chinese individuals aged 65-74 years in the south ( $n$ 405; - $)$ and the north ( $n$ 405; - - - ) of China, 2006

Table 2 Plasma homocysteine levels ( $\mu \mathrm{mol} / \mathrm{l})$ according to demographic and lifestyle factors by region: elderly Chinese individuals $(n 810)$ aged $65-74$ years, 2006

\begin{tabular}{|c|c|c|c|c|c|c|}
\hline & \multicolumn{3}{|c|}{ North } & \multicolumn{3}{|c|}{ South } \\
\hline & $n$ & Geometric mean & $95 \% \mathrm{Cl}$ & $n$ & Geometric mean & $95 \% \mathrm{Cl}$ \\
\hline Overall & 405 & $18 \cdot 42$ & $17 \cdot 40,19 \cdot 50$ & 405 & $10 \cdot 20$ & $9 \cdot 84,10 \cdot 58$ \\
\hline \multicolumn{7}{|l|}{ Age } \\
\hline $65-69$ years & 203 & $17 \cdot 68$ & $16 \cdot 36,19 \cdot 11$ & 203 & $9 \cdot 99$ & $9 \cdot 44,10 \cdot 57$ \\
\hline $70-74$ years & 202 & $19 \cdot 18$ & $17 \cdot 66,20 \cdot 91$ & 202 & $10 \cdot 42$ & $9 \cdot 94,10 \cdot 92$ \\
\hline \multicolumn{7}{|l|}{ Gender } \\
\hline Male & 202 & $21 \cdot 14^{\star \star}$ & $19 \cdot 54,23 \cdot 00$ & 201 & $11 \cdot 14^{\star \star}$ & $10 \cdot 52,11 \cdot 78$ \\
\hline Female & 203 & $16 \cdot 06$ & $14 \cdot 87,17 \cdot 33$ & 204 & $9 \cdot 36$ & $8 \cdot 96,9 \cdot 78$ \\
\hline \multicolumn{7}{|l|}{ Occupation } \\
\hline Farmer & 387 & $18 \cdot 34$ & $17 \cdot 31,19 \cdot 46$ & 347 & $10 \cdot 20$ & $9 \cdot 79,10 \cdot 62$ \\
\hline Others & 18 & $20 \cdot 04$ & $14 \cdot 85,27 \cdot 04$ & 58 & $10 \cdot 24$ & $9 \cdot 40,11 \cdot 15$ \\
\hline \multicolumn{7}{|l|}{ Educational background } \\
\hline Illiterate & 175 & $17 \cdot 91$ & $16 \cdot 44,19 \cdot 51$ & 204 & $9 \cdot 57^{* *}$ & $9 \cdot 14,10 \cdot 02$ \\
\hline Junior school or higher & 230 & $18 \cdot 81$ & $17 \cdot 43,20 \cdot 35$ & 201 & $10 \cdot 89$ & $10 \cdot 29,11 \cdot 52$ \\
\hline \multicolumn{7}{|l|}{$\mathrm{BMI}\left(\mathrm{kg} / \mathrm{m}^{2}\right)$} \\
\hline$<24$ & 247 & $18 \cdot 24$ & $17 \cdot 02,19 \cdot 58$ & 224 & $10 \cdot 43$ & $9 \cdot 90,10 \cdot 99$ \\
\hline$\geq 24$ & 158 & $18 \cdot 70$ & $16 \cdot 95,20 \cdot 63$ & 181 & $9 \cdot 93$ & $9 \cdot 44,10 \cdot 44$ \\
\hline \multicolumn{7}{|l|}{ Hypertension } \\
\hline Yes & 270 & $18 \cdot 89$ & $17 \cdot 58,20 \cdot 32$ & 199 & $10 \cdot 06$ & $9 \cdot 57,10 \cdot 57$ \\
\hline No & 135 & $17 \cdot 51$ & $15.97,19.22$ & 206 & $10 \cdot 35$ & $9 \cdot 80,10 \cdot 92$ \\
\hline \multicolumn{7}{|l|}{ Current smoking } \\
\hline Yes & 103 & $21 \cdot 03^{\star \star}$ & $19 \cdot 03,23 \cdot 50$ & 110 & $10 \cdot 98^{\star \star}$ & $10 \cdot 15,11 \cdot 87$ \\
\hline No & 302 & $17 \cdot 60$ & $16 \cdot 45,18 \cdot 83$ & 295 & $9 \cdot 93$ & $9 \cdot 53,10 \cdot 34$ \\
\hline \multicolumn{7}{|l|}{ Ever smoking } \\
\hline Yes & 107 & $21 \cdot 31^{\star *}$ & $19 \cdot 29,23 \cdot 80$ & 154 & $10 \cdot 99^{\star \star}$ & $10 \cdot 31,11 \cdot 70$ \\
\hline No & 298 & $17 \cdot 48$ & $16 \cdot 34,18 \cdot 69$ & 251 & $9 \cdot 75$ & $9 \cdot 33,10 \cdot 19$ \\
\hline \multicolumn{7}{|l|}{ Alcohol consumption } \\
\hline Yes & 64 & $18 \cdot 13$ & $15 \cdot 74,20 \cdot 88$ & 115 & $10 \cdot 35$ & $9 \cdot 79,10 \cdot 95$ \\
\hline No & 339 & $18 \cdot 49$ & $17 \cdot 36,19 \cdot 69$ & 290 & $10 \cdot 15$ & $9 \cdot 69,10 \cdot 63$ \\
\hline
\end{tabular}

${ }^{\star *} P<0.01$.

farmers, with higher education and those with hypertension were associated with a greater risk of HHCY to some extent. Interestingly, alcohol consumption showed protective effects for alcohol drinkers, with about $40 \%$ (unadjusted $\mathrm{OR}=0.58$ ) or $50 \%$ (adjusted $\mathrm{OR}=0.50$ ) reduced risk for elevated Hcy compared with non-drinkers. 
Table 3 Hyperhomocysteinaemia prevalence rates (\%) according to demographic and lifestyle factors by region: elderly Chinese individuals ( $n$ 810) aged 65-74 years, 2006

\begin{tabular}{|c|c|c|c|c|c|c|}
\hline & \multicolumn{3}{|c|}{ North (n 405) } & \multicolumn{3}{|c|}{ South ( $n$ 405) } \\
\hline & $n$ & Mean & $95 \% \mathrm{Cl}$ & $n$ & Mean & $95 \% \mathrm{Cl}$ \\
\hline $\begin{array}{l}\text { Overall } \\
\text { Age }\end{array}$ & 209 & $51 \cdot 6$ & $46 \cdot 6,56 \cdot 6$ & 41 & $10 \cdot 1$ & $7 \cdot 4,13 \cdot 6$ \\
\hline 65-69 years & 98 & $48 \cdot 3$ & $41 \cdot 3,55 \cdot 4$ & 18 & 8.9 & $5.5,13.9$ \\
\hline $70-74$ years & 111 & $55 \cdot 0$ & $47 \cdot 8,61 \cdot 9$ & 23 & $11 \cdot 4$ & $7 \cdot 5,16 \cdot 8$ \\
\hline \multicolumn{7}{|l|}{ Gender } \\
\hline Male & 123 & $60 \cdot 9^{\star \star}$ & $53 \cdot 8,67 \cdot 6$ & 25 & $12 \cdot 4$ & $8 \cdot 4,18 \cdot 0$ \\
\hline Female & 86 & $42 \cdot 4$ & $35 \cdot 5,49 \cdot 5$ & 16 & $7 \cdot 8$ & $4 \cdot 7,12 \cdot 7$ \\
\hline \multicolumn{7}{|l|}{ Occupation } \\
\hline Farmer & 200 & $51 \cdot 7$ & $46 \cdot 6,56 \cdot 8$ & 36 & $10 \cdot 4$ & $7 \cdot 5,14 \cdot 2$ \\
\hline Others & 9 & $50 \cdot 0$ & $26 \cdot 8,73 \cdot 2$ & 5 & $8 \cdot 6$ & $3 \cdot 2,19 \cdot 7$ \\
\hline \multicolumn{7}{|l|}{ Educational background } \\
\hline Illiterate & 85 & $48 \cdot 6$ & $41 \cdot 0,56 \cdot 2$ & 14 & $6 \cdot 9$ & $3 \cdot 9,11 \cdot 5$ \\
\hline Junior school or higher & 124 & 53.9 & $47 \cdot 2,60 \cdot 5$ & 27 & $13 \cdot 4$ & $9 \cdot 2,19 \cdot 1$ \\
\hline \multicolumn{7}{|l|}{ BMI $\left(\mathrm{kg} / \mathrm{m}^{2}\right)$} \\
\hline$<24$ & 128 & $51 \cdot 8$ & $45 \cdot 4,58 \cdot 2$ & 25 & $11 \cdot 2$ & $7 \cdot 5,16 \cdot 2$ \\
\hline$\geq 24$ & 81 & $51 \cdot 3$ & $43 \cdot 2,59 \cdot 3$ & 16 & $8 \cdot 8$ & $5 \cdot 3,14 \cdot 2$ \\
\hline \multicolumn{7}{|l|}{ Hypertension } \\
\hline Yes & 140 & $51 \cdot 9$ & $45 \cdot 7,57 \cdot 9$ & 19 & $9 \cdot 6$ & $6 \cdot 0,14 \cdot 7$ \\
\hline No & 69 & $51 \cdot 1$ & $42 \cdot 4,59 \cdot 8$ & 22 & $10 \cdot 7$ & $7 \cdot 0,15 \cdot 9$ \\
\hline \multicolumn{7}{|l|}{ Current smoking } \\
\hline Yes & 62 & $60 \cdot 2^{*}$ & $50 \cdot 1,69 \cdot 6$ & 12 & $10 \cdot 9$ & $6 \cdot 0,18 \cdot 6$ \\
\hline No & 147 & $48 \cdot 7$ & $42 \cdot 9,54 \cdot 5$ & 29 & $9 \cdot 8$ & $6 \cdot 8,14 \cdot 0$ \\
\hline \multicolumn{7}{|l|}{ Ever smoking } \\
\hline Yes & 65 & $60 \cdot 8^{\star}$ & $50 \cdot 8,69 \cdot 9$ & 18 & $11 \cdot 7$ & $7 \cdot 3,18 \cdot 1$ \\
\hline No & 144 & $48 \cdot 3$ & $42 \cdot 5,54 \cdot 2$ & 23 & $9 \cdot 2$ & $6 \cdot 0,13 \cdot 6$ \\
\hline \multicolumn{7}{|l|}{ Alcohol consumption } \\
\hline Yes & 31 & $48 \cdot 4$ & $35 \cdot 9,61 \cdot 2$ & 9 & $7 \cdot 8$ & $3 \cdot 9,14 \cdot 7$ \\
\hline No & 177 & $52 \cdot 2$ & $46 \cdot 8,57 \cdot 6$ & 32 & $11 \cdot 0$ & $7 \cdot 8,15 \cdot 4$ \\
\hline
\end{tabular}

${ }^{\star} P<0.05,{ }^{* *} P<0.01$

Table 4 Crude and adjusted odds ratios, and their $95 \%$ confidence intervals, of hyperhomocysteinaemia by demographic and lifestyle factors: elderly Chinese individuals ( $n$ 810) aged 65-74 years, 2006

\begin{tabular}{|c|c|c|c|c|c|c|}
\hline \multirow[b]{2}{*}{ Factor } & \multicolumn{6}{|c|}{ Hyperhomocysteinaemia } \\
\hline & Yes, $n$ & No, $n$ & Crude OR & $95 \% \mathrm{Cl}$ & Adjustedt OR & $95 \% \mathrm{Cl}$ \\
\hline \multicolumn{7}{|l|}{ Region } \\
\hline North & 209 & 196 & $9 \cdot 47^{* *}$ & $6 \cdot 49,13 \cdot 80$ & $9 \cdot 16^{* *}$ & $6 \cdot 16,13 \cdot 63$ \\
\hline South & 41 & 364 & 1.00 & ref. & $1 \cdot 00$ & ref. \\
\hline \multicolumn{7}{|l|}{ Age } \\
\hline $65-69$ years & 116 & 290 & 1.00 & ref. & 1.00 & ref. \\
\hline $70-74$ years & 134 & 270 & $1 \cdot 24$ & $0.92,1.67$ & $1 \cdot 35$ & $0.95,1.93$ \\
\hline \multicolumn{7}{|l|}{ Gender } \\
\hline Male & 148 & 255 & $1 \cdot 74^{*}$ & $1 \cdot 28,2 \cdot 35$ & $2 \cdot 39^{\star *}$ & $1 \cdot 50,3 \cdot 81$ \\
\hline Female & 102 & 305 & $1 \cdot 00$ & ref. & $1 \cdot 00$ & ref. \\
\hline \multicolumn{7}{|l|}{ Occupation } \\
\hline Farmer & 236 & 498 & $2 \cdot 10^{\star *}$ & $1 \cdot 15,3 \cdot 83$ & $1 \cdot 52$ & $0.75,3.08$ \\
\hline Others & 14 & 62 & 1.00 & ref. & 1.00 & ref. \\
\hline \multicolumn{7}{|l|}{ Educational background } \\
\hline Illiterate & 99 & 280 & $1 \cdot 00$ & ref. & $1 \cdot 00$ & ref. \\
\hline Junior school or higher & 151 & 280 & $1 \cdot 53^{\star \star}$ & $1 \cdot 13,2 \cdot 07$ & $1 \cdot 25$ & $0.84,1 \cdot 84$ \\
\hline \multicolumn{7}{|l|}{ BMI $\left(\mathrm{kg} / \mathrm{m}^{2}\right)$} \\
\hline$<24$ & 153 & 318 & $1 \cdot 00$ & ref. & $1 \cdot 00$ & ref. \\
\hline$\geq 24$ & 97 & 242 & 0.83 & $0 \cdot 61,1 \cdot 13$ & 1.05 & $0.73,1.50$ \\
\hline \multicolumn{7}{|l|}{ Hypertension } \\
\hline Yes & 159 & 310 & $1 \cdot 41^{\star *}$ & $1 \cdot 04,1.92$ & 0.99 & $0.69,1.42$ \\
\hline No & 91 & 250 & 1.00 & ref. & $1 \cdot 00$ & ref. \\
\hline \multicolumn{7}{|l|}{ Current smoking } \\
\hline Yes & 74 & 139 & $1 \cdot 27$ & $0.91,1 \cdot 78$ & $1 \cdot 00$ & $0 \cdot 62,1 \cdot 62$ \\
\hline No & 176 & 421 & 1.00 & ref. & $1 \cdot 00$ & ref. \\
\hline \multicolumn{7}{|l|}{ Alcohol consumption } \\
\hline Yes & 40 & 139 & $0.58^{\star *}$ & $0.39,0.85$ & $0.50^{\star *}$ & $0.30,0.81$ \\
\hline No & 209 & 420 & $1 \cdot 00$ & ref. & 1.00 & ref. \\
\hline
\end{tabular}

${ }^{*} P<0.05,{ }^{* *} P<0.01$.

tAdjusted for region, gender, age, BMI, occupation, educational background, hypertension, current smoking and alcohol consumption. All variables used in the adjusted model were dichotomous variables. 
However, adjustment for the interactions between factors had no important effects on most of these associations except for region, gender and alcohol consumption.

Furthermore, subgroup analyses were conducted in male smokers (because very few women smoked in this population) and in postmenopausal women with HHCY. No significant associations were found in either analysis (data not shown).

\section{Nutritional factors}

Finally, we assessed the correlation between Hcy and plasma folate. Overall, plasma Hcy was inversely correlated with plasma folate (Spearman's $r=-0 \cdot 44, P<0 \cdot 001$ ) as expected. After adjusting for all other factors the inverse relationship still remained, resulting in a significant coefficient (partial correlation $r=-0 \cdot 229, P<0 \cdot 001$ ). Among subjects with high Hcy levels, deficits of plasma folate were more prevalent in individuals from the north than in those from the south, 33\% v. 29\%, respectively. In contrast, $80 \%$ of northerners and $38 \%$ of southerners with low plasma folate showed high Hcy levels.

\section{Discussion}

\section{High prevalence rate of byperbomocysteinaemia}

To our knowledge, the present study is the first to report data on Hcy concentrations by demographic and lifestyle factors in an elderly Chinese population. We found a high prevalence of $\mathrm{HHCY}$ in this population, in particular among the men $(61 \%)$ living in north China. Notable geographic and gender variations were observed for plasma Hcy concentrations among the study population, which may be the combined results of demographic and lifestyle factors, nutritional status and genetic backgrounds.

\section{Gender, age and alcohol consumption}

The largest population-based study, The Hordaland Homocysteine Study, demonstrated that Hcy concentrations increased with age and were higher in men than in women $^{(10)}$. Detailed data on the Hcy levels of the elderly have also been reported from the third US National Health and Nutrition Examination Survey (NHANES III) ${ }^{(11)}$ and in other studies around the world ${ }^{(12-24)}$. Our study observed that Hcy levels were higher in men than in women, which is in agreement with the results of the Hordaland study. The male-female differences in Hcy concentrations probably result from the fact that renal cystathionine $\beta$-synthase activity is significantly lower in men than women, leading to higher Hcy levels by decreased conversion of Hcy to cysteine in the transsulfuration pathway ${ }^{(25)}$. However, we did not find significant differences in Hcy concentrations between the two age groups (65-69v v 70-74 years old), perhaps because the age span was smaller than 10 years. Our sample size was large enough that we can exclude the possibility of lacking power for non-significant differences.
Additionally, our data confirmed the inverse association between Hcy levels and alcohol consumption reported by the Caerphilly cohort study ${ }^{(26)}$. The possible explanations include, on the one hand, that the predominant type of alcoholic beverage (i.e. beer) consumed contains folate and that drinkers were likely to consume more food rich in folate (e.g. meat), on the other. These may indirectly improve folate status and decrease Hcy levels.

\section{Regional variations}

Overall, the south-north differences observed among the Chinese elderly population are consistent with previous published results from other younger populations. However, it is notable that the absolute prevalence rates of HHCY and the differences in Hcy levels between the two regions were more distinct in the elderly. The larger regional disparities could be explained, in part, by increasing age and different eating habits in the two regions. Moreover, genetic polymorphisms may be another essential factor. It has been reported that persons with the 5,10-methylenetetrahydrofolate reductase (MTHFR) 677-TT genotype have a $25.7 \%$ higher Hcy concentration than those with the $677-$ CC genotype ${ }^{(27)}$. Furthermore, several studies have pointed out that northerners have higher $T T$ genotype frequency than southerners ${ }^{(28,29)}$. Therefore, the MTHFR C677T polymorphism may explain, in part, the higher prevalence of HHCY in the north.

In addition, low plasma folate status might account for portions of these variations ${ }^{(30)}$. Individuals with elevated Hcy concentrations in our study also had low plasma folate concentrations and higher prevalence of deficits, with $10.06 \mathrm{nmol} / 1$ and $31 \cdot 0 \%$ in the north $v .14 \cdot 17 \mathrm{nmol} / 1$ and $7 \cdot 7 \%$ in the south. We also found that a negative correlation between plasma folate levels and Hcy concentrations existed independent of other demographic and lifestyles factors, suggesting that plasma folate might be an important nutritional factor affecting Hcy levels in the two regions.

\section{Comparison of byperbomocysteinaemia prevalence between elderly populations in China and developed countries}

The NHANES III study (1991-1994) defined HHCY as Hcy level higher than $11.4 \mu \mathrm{mol} / \mathrm{l}$ in male and $10.4 \mu \mathrm{mol} / \mathrm{l}$ in female populations who had good nutritional status and normal renal functioning ${ }^{(11)}$. On the basis of these criteria, the prevalence of HHCY in our study was converted into $83.7 \%$ in the north and $34.3 \%$ in the south. These high prevalence rates are twice those in Americans $(\geq 60$ years old), which are $43.2 \%$ and $46.5 \%$ for men and women, respectively. Since 1998, food fortification with folic acid has been implemented in the USA. The latest NHANES study showed that the average Hcy levels of the US population have declined by $8-10 \%$ in men and by $3-13 \%$ in women. Similarly, Hcy levels of the elderly have changed from $12.5 \mu \mathrm{mol} / 1$ before to $9 \cdot 8 \mu \mathrm{mol} / 1$ after 
fortification ${ }^{(31,32)}$. These findings suggest that even compared with the American elderly population living 20 years ago, the prevalence of HHCY among Chinese elderly is nearly two times greater, and might be much higher than the current levels of the American elderly.

In a cohort of elderly survivors from the Framingham study population, mean Hcy concentration was $11.9 \mu \mathrm{mol} / \mathrm{l}$; values higher than $14 \mu \mathrm{mol} / 1$ were detected in $29 \cdot 3 \%$ of the subjects $^{(33)}$. Under these criteria, our study found $63.7 \%$ of northerners and $16 \cdot 3 \%$ of southerners had high Hcy levels.

Recently, a community-based prospective cohort study in Taiwan evaluated the cut-off point of Hcy for predicting risk of vascular diseases and death. Hcy levels were found to be statistically significantly related to cardiovascular events and all-cause deaths, with the best cut-off values being $9 \cdot 47 \mu \mathrm{mol} / \mathrm{l}$ and $11.84 \mu \mathrm{mol} / \mathrm{l}$, respectively ${ }^{(34)}$. Nygard et al. previously pointed out that Hcy values $\leq 9 \mu \mathrm{mol} / \mathrm{l}$ were associated with the lowest mortality level in CVD patients ${ }^{(35)}$. In our study, $91 \cdot 1 \%$ of northerners and $59.8 \%$ of southerners were found to be at risk of vascular diseases and death when $9 \mu \mathrm{mol} / \mathrm{l}$ was adopted. This finding implies that the elevated Hcy levels among Chinese elderly populations need to be decreased urgently.

Besides CVD and death, Hcy levels have also been reported to be associated with an increased risk of Alzheimer's disease ${ }^{(36,37)}$ and colon cancer ${ }^{(38)}$ in older individuals. Until ongoing and completed intervention trials with folate in patients with chronic diseases obtain a definite conclusion on the potential roles of HHCY in these diseases, the observed lifestyle-Hcy relationships may contribute to the understanding of the aetiology and to possible prevention of some of these clinical conditions.

One limitation of the present study was the cross-sectional design with blood samples collected only in winter. These made it impossible to evaluate the data in terms of cause-and-effect relationships and we were unable to determine the impact of seasonal factors on Hcy levels. Moreover, our study sample was not a random sample of all the local populations; but on account of the stabilization of the local elderly population as well as their similar dietary habits and lifestyle, they were fairly representative of the eligible target elderly population living in the two regions. However, our study provided strong evidence of a high level of Hcy and a high prevalence of HHCY with distinct regional variations. These data are particularly important in the case of elderly populations who have a high absolute risk of vascular disease, and for whom individualized interventions with folate should be of most benefit.

\section{Acknowledgements}

Sources of funding: The study was supported by the National Nature Science Foundation, People's Republic of China (Grant No. 30572071 and 30471486). The work of
Q.Q. was supported by funds from Peking University Health Science Center, Beijing, People's Republic of China (Grant No. BMU20090464-123). Conflict of interest declaration: The authors declare that there are no conflicts of interest. Author contributions: Q.-G.Q. conceptualized the paper, prepared data, conducted the statistical analysis, drafted and edited the manuscript. J.-J.G. was responsible for the field sites and data collection. J.-M.L. was the project leader, responsible for design, general coordination and supervision. Acknowledgements: We are deeply indebted to every health worker who participated in the survey for attending training sessions and collecting data, and to those participants from our two field sites for their devotion to the study.

\section{References}

1. Boushey CJ, Beresford SA, Omenn GS et al. (1995) A quantitative assessment of plasma homocysteine as a risk factor for vascular disease. Probable benefits of increasing folic acid intakes. JAMA 274, 1049-1057.

2. Homocysteine Studies Collaboration (2002) Homocysteine and risk of ischemic heart disease and stroke: a metaanalysis. JAMA 288, 2015-2022.

3. Moustapha A \& Robinson K (1998) High plasma homocysteine: a risk factor for vascular disease in the elderly. Coron Artery Dis 9, 725-730.

4. Kannel WB (1997) Cardiovascular risk factors in the elderly. Coron Artery Dis 8, 565-575.

5. Bates CJ, Schneede J, Mishra G et al. (2003) Relationship between methylmalonic acid, homocysteine, vitamin $B_{12}$ intake and status and socio-economic indices, in a subset of participants in the British National Diet and Nutrition Survey of people aged 65 y and over. Eur J Clin Nutr 57, 349-357.

6. McCully KS (2007) Homocysteine, vitamins, and vascular disease prevention. Am J Clin Nutr 86, 1563S-1568S.

7. O'Broin S \& Kelleher B (1992) Microbiological assay on microtitre plates of folate in serum and red cells. J Clin Pathol 45, 344-347.

8. Ueland PM, Refsum H, Stabler SP et al. (1993) Total homocysteine in plasma or serum: methods and clinical applications. Clin Chem 39, 1764-1779.

9. Senti FR \& Pilch SM (1984) Assessment of the Folate Nutritional Status of the US Population Based on Data Collected in the Second National Health and Nutrition Examination Survey, 1976-1980. Bethesda, MD: Federation of American Societies for Experimental Biology.

10. Nygard O, Vollset SE, Refsum H et al. (1995) Total plasma homocysteine and cardiovascular risk profile. The Hordaland Homocysteine Study. JAMA 274, 1526-1533.

11. Selhub J, Jacques PF, Rosenberg IH et al. (1999) Serum total homocysteine concentrations in the third National Health and Nutrition Examination Survey (1991-1994): population reference ranges and contribution of vitamin status to high serum concentrations. Ann Intern Med 131, 331-339.

12. Hoey L, McNulty H, Askin N et al. (2007) Effect of a voluntary food fortification policy on folate, related B vitamin status, and homocysteine in healthy adults. $\mathrm{Am} \mathrm{J}$ Clin Nutr 86, 1405-1413.

13. Carlsson CM, Pharo LM, Aeschlimann SE et al. (2004) Effects of multivitamins and low-dose folic acid supplements on flow-mediated vasodilation and plasma homocysteine levels in older adults. Am Heart J 148, E11.

14. Gunstad J, Bausserman L, Paul RH et al. (2006) C-reactive protein, but not homocysteine, is related to cognitive dysfunction in older adults with cardiovascular disease. J Clin Neurosci 13, 540-546. 
15. Sutton-Tyrrell K, Bostom A, Selhub J et al. (1997) High homocysteine levels are independently related to isolated systolic hypertension in older adults. Circulation 96 $1745-1749$.

16. Lim HS \& Heo YR (2002) Plasma total homocysteine, folate, and vitamin $\mathrm{B}_{12}$ status in Korean adults. J Nutr Sci Vitaminol (Tokyo) 48, 290-297.

17. Hambaba L, Abdessemed S, Yahia M et al. (2008) [Relationship between hyperhomocysteinemia and C677T polymorphism of methylene tetrahydrofolate reductase gene in a healthy Algerian population]. Ann Biol Clin (Paris) 66, 637-641.

18. Fakhrzadeh H, Ghotbi S, Pourebrahim R et al. (2006) Total plasma homocysteine, folate, and vitamin $\mathrm{B}_{12}$ status in healthy Iranian adults: the Tehran homocysteine survey (2003-2004)/a cross-sectional population based study. BMC Public Health 6, 29.

19. van Oort FV, Melse-Boonstra A, Brouwer IA et al. (2003) Folic acid and reduction of plasma homocysteine concentrations in older adults: a dose-response study. Am J Clin Nutr 77, 1318-1323.

20. Schafer JH, Glass TA, Bolla KI et al. (2005) Homocysteine and cognitive function in a population-based study of older adults. J Am Geriatr Soc 53, 381-388.

21. Koike T, Kuzuya M, Kanda S et al. (2008) Raised homocysteine and low folate and vitamin B-12 concentrations predict cognitive decline in community-dwelling older Japanese adults. Clin Nutr 27, 865-871.

22. Kuo HK, Liao KC, Leveille SG et al. (2007) Relationship of homocysteine levels to quadriceps strength, gait speed, and late-life disability in older adults. J Gerontol A Biol Sci Med Sci 62, 434-439.

23. Feng L, Ng TP, Chuah L et al. (2006) Homocysteine, folate, and vitamin B-12 and cognitive performance in older Chinese adults: findings from the Singapore Longitudinal Ageing Study. Am J Clin Nutr 84, 1506-1512.

24. Bunout D, Petermann M, de la Maza P et al. (1998) [Serum homocysteine levels in healthy Chilean adults]. Rev Med Chil 126, 905-910.

25. Vitvitsky V, Prudova A, Stabler S et al. (2007) Testosterone regulation of renal cystathionine $\beta$-synthase: implications for sex-dependent differences in plasma homocysteine levels. Am J Physiol Renal Physiol 293, F594-F600.

26. Ubbink JB, Fehily AM, Pickering J et al. (1998) Homocysteine and ischaemic heart disease in the Caerphilly cohort. Atherosclerosis 140, 349-356.
27. Yang QH, Botto LD, Gallagher M et al. (2008) Prevalence and effects of gene-gene and gene-nutrient interactions on serum folate and serum total homocysteine concentrations in the United States: findings from the third National Health and Nutrition Examination Survey DNA Bank. Am J Clin Nutr 88, 232-246.

28. Chu JY, Huang W, Kuang SQ et al. (1998) Genetic relationship of populations in China. Proc Natl Acad Sci U S A 95, 11763-11768.

29. Wilcken B, Bamforth F, Li Z et al. (2003) Geographical and ethnic variation of the $677 \mathrm{C}>\mathrm{T}$ allele of 5,10-methylenetetrahydrofolate reductase (MTHFR): findings from over 7000 newborns from 16 areas worldwide. J Med Genet $\mathbf{4 0}$, 619-625.

30. Joosten E, Pelemans W, Devos P et al. (1993) Cobalamin absorption and serum homocysteine and methylmalonic acid in elderly subjects with low serum cobalamin. Eur J Haematol 51, 25-30.

31. Ganji V \& Kafai MR (2006) Population reference values for plasma total homocysteine concentrations in US adults after the fortification of cereals with folic acid. Am J Clin Nutr 84, 989-994.

32. Pfeiffer CM, Osterloh JD, Kennedy-Stephenson $\mathrm{J}$ et al. (2008) Trends in circulating concentrations of total homocysteine among US adolescents and adults: findings from the 1991-1994 and 1999-2004 National Health and Nutrition Examination Surveys. Clin Chem 54, 801-813.

33. Selhub J, Jacques PF, Wilson PW et al. (1993) Vitamin status and intake as primary determinants of homocysteinemia in an elderly population. JAMA 270, 2693-2698.

34. Sun Y, Chien KL, Hsu HC et al. (2009) Use of serum homocysteine to predict stroke, coronary heart disease and death in ethnic Chinese. Circ J 73, 1423-1430.

35. Nygard O, Nordrehaug JE, Refsum H et al. (1997) Plasma homocysteine levels and mortality in patients with coronary artery disease. $N$ Engl J Med 337, 230-236.

36. Clarke R, Smith AD, Jobst KA et al. (1998) Folate, vitamin $\mathrm{B}_{12}$, and serum total homocysteine levels in confirmed Alzheimer disease. Arch Neurol 55, 1449-1455.

37. McCaddon A, Davies G, Hudson P et al. (1998) Total serum homocysteine in senile dementia of Alzheimer type. Int J Geriatr Psychiatry 13, 235-239.

38. Kato I, Dnistrian AM, Schwartz M et al. (1999) Serum folate, homocysteine and colorectal cancer risk in women: a nested case-control study. Br J Cancer 79, 1917-1922. 